\title{
Countertransference in the initial visit of women victims of sexual violence
}

\section{Contratransferência no atendimento inicial de mulheres vítimas de violência sexual}

\author{
Mariana Eizirik, ${ }^{1}$ Sidnei Schestatsky, ${ }^{1,2}$ Letícia Kruel, ${ }^{1}$ Lúcia Helena Freitas Ceitlin ${ }^{1,2}$ \\ ${ }^{1}$ Center for the Study and Treatment of Psychological Trauma (NET-TRAUMA), Hospital de Clínicas de Porto Alegre (HCPA), Porto Alegre, RS, \\ Brazil \\ ${ }^{2}$ Department of Psychiatry and Legal Medicine, Universidade Federal do Rio Grande do Sul (UFRGS), Porto Alegre, RS, Brazil
}

\begin{abstract}
Objective: To identify demographic and clinical correlates associated with therapists' countertransference feelings on the first visit of women victims of sexual violence. Method: Forty patients were seen by 26 therapists, during 2 consecutive years, at the Center for the Study and Treatment of Psychological Trauma, Hospital de Clínicas de Porto Alegre, Brazil. After the first visit with the patient, the therapist completed the Assessment of Countertransference Scale and the patient was evaluated with the Davidson Trauma Scale, the Standardized Assessment of Personality - Abbreviated Scale, the Beck Depression Inventory, and the Defense Style Questionnaire. Results: The therapists showed a predominance of feelings of closeness (Mean $=5.42, \mathrm{SD}=1.25)$ in relation to the feelings of indifference $($ Mean $=1.82, \mathrm{SD}=1.22)$ and distance $($ Mean $=1.57, \mathrm{SD}=1.08)[\mathrm{p}<0.001]$. Multivariate analyses did not present significant associations between countertransference feelings and clinical characteristics of patients. The gender of the therapists did not influence the pattern of countertransference feelings. In the subgroup of female therapists, we detected an inverse correlation between a higher probability of patients' personality disorders and feelings of closeness in the therapists. Conclusion: We did not detect a differential pattern of countertransference feelings associated with specific clinical characteristics. Therapists of both genders presented a similar pattern of feelings of empathy towards women victims of sexual violence, although the gender of the therapist may moderate the feelings evoked by patients with increased likelihood of personality disorders.
\end{abstract}

Descriptors: Countertransference; Violence; Sexual abuse; Trauma; Psychotherapy

\section{Resumo}

Objetivo: Identificar os correlatos demográficos e clinicos associados com sentimentos contratransferenciais de terapeutas na primeira consulta de mulheres vitimas de violência sexual. Método: Quarenta pacientes foram atendidas por 26 terapeutas, ao longo de dois anos consecutivos, no Núcleo de Estudos e Tratamento do Trauma Psíquico do Hospital de Clínicas de Porto Alegre, Brasil. Após a primeira consulta com a paciente, o terapeuta preenchia a Escala para Avaliação da Contratransferência. Os pacientes foram avaliados com a Escala Davidson de Trauma, a Standardized Assessment of Personality - Abbreviated Scale, o Inventário de Depressão de Beck, e a versão em português do Defense Style Questionaire. Resultados: Os terapeutas apresentaram predominantemente sentimentos de proximidade (Mean $=5,42$, $S D=1,25)$ em comparação aos sentimentos de indiferença (Mean $=1,82$, $S D=1,22)$ e de distanciamento (Mean $=1,57, S D=1,08)[p<0,001]$. As análises multivariadas revelaram a ausência de associaçôes entre os sentimentos contratransferenciais e características clínicas dos pacientes. O gênero dos terapeutas não influenciou o padrão de sentimentos contratransferenciais. No subgrupo de terapeutas mulheres, detectamos uma correlação inversa entre alta probabilidade de transtornos de personalidade nos pacientes e sentimentos de aproximação dos terapeutas. Conclusão: Não detectamos um padrão diferencial de sentimentos contratransferenciais associados com características clínicas especificas. Terapeutas de ambos os gêneros apresentaram um padrão similar de sentimentos de empatia em relação a mulheres vítimas de violência sexual, embora o gênero do terapeuta possa moderar os sentimentos evocados por pacientes com alta probabilidade de transtornos de personalidade.

Descritores: Contratransferência; Violência; Abuso sexual; Trauma; Psicoterapia

\section{Introduction}

The concept of countertransference was introduced by Freud and expanded by authors such as Heimann, Racker and Winnicot, and was understood as the emotional reactions triggered by patients in the therapists. ${ }^{1-4}$ It is pivotal in the current psychoanalytic theory and technique, since it is an important tool to understand patients' reports and their internal world, influencing the therapeutic relationship and the outcome of the treatment. Gabbard remarks that countertransference may be considered as a joint creation of the therapeutic dyad, and there is currently a consensus for its use in understanding patients. ${ }^{5}$ 
Acknowledging the importance of the therapist's mind and the therapeutic field, there has been a growing debate on the association between characteristics of the real person of the therapist, such as gender, and the way that the relationship with the patient is established. ${ }^{6,7}$ Likewise, after Winnicot, ${ }^{4}$ specific characteristics of the patients, as their different psychopathologies, were considered as potential triggers of countertransference responses with constant patterns. ${ }^{8,9}$

Studies by Rossberg et al. and Betan et al. depict recent research addressing the relationship between countertransference patterns and personality disorders. ${ }^{10,11}$ The first study ${ }^{10}$ has shown that there are differences in therapists' countertransference reactions towards patients with different personality disorders, as well as the relationship between countertransference feelings and the direction of treatments. The study by Betan et al. showed significant correlation between specific countertransference patterns and personality disorders. ${ }^{11}$ This suggests that countertransference responses may arise in a coherent and predictable manner, which strengthens its use for diagnostic unraveling and treatment of patients. The results of these studies support the possibility and the importance of identifying countertransference patterns triggered by patients with different psychiatric diagnoses, or by those sharing previous traumatic experiences, such as a history of sexual violence. ${ }^{11}$

The relevance of studying countertransference feelings triggered by victims of sexual violence is justified because of their high intensity and because of the likelihood of such emotional reactions becoming barriers for a successful treatment, when they are not understood by the therapist. ${ }^{12}$ It is known that therapeutic impasses and failures are fairly common in treating victims of psychological trauma. ${ }^{13}$ The therapists may be the first ones to identify, within themselves, feelings such as fear, shame and helplessness in patients, because, at first, patients may not always be able to access their affective experiences. As these feelings are often intense and even unbearable, they may terrify the therapeutic dyad, leading to impasses if not recognized and elaborated. ${ }^{14}$

In working with patients who were sexually abused, clinicians frequently face the opposite risk of either pressing too much the patient to remember, or avoiding discussion of the traumatic event in detail. The latter situation results for fear of traumatizing the patient, and potentially repeats patients' experience of unacknowledged but shared secrets. Identification of such models as common pattern in the treatment of abuse survivors could be very useful in teaching clinicians about potential countertransference risks when working with these patients in a way that is both clinically sensitive and empirically grounded. ${ }^{11}$

The occurrence of sexual abuse or violence during childhood may be associated with the development of specific psychopathology, especially mood and personality disorders, which might also be related to specific countertransference responses. ${ }^{8,9,15-17}$ One of the possible mediators in the appearance of such disorders is the use of more immature defense mechanisms by the victims, a phenomenon commonly associated with this trauma. ${ }^{18,19}$
Prevalence studies reveal that lifetime sexual abuse in women ranges between $15 \%$ and $25 \% .{ }^{15}$ Caring for these patients generates a large burden to the health professionals, especially those from mental health services, who have to face situations of strong emotional impact, and often difficult to understand. A greater understanding of the countertransference arising from these contacts may facilitate the recognition and elaboration of the feelings emerged, reducing the chances that they become obstacles to understand patients.

In the present study, we assessed the countertransference feelings of therapists towards female victims of sexual violence at their first appointment at a clinic specialized in the treatment of psychological trauma. Our aim was to determine whether the following factors were independently associated with therapists' countertransference: time within the visit, therapist's gender, time when sexual violence occurred in the patient's life, the presence of depressive and PTSD symptoms in patients, scores in the scales of disease severity perception and in screening for personality disorders in the patients, and patients' defensive style.

\section{Method \\ 1. Setting}

The study was carried out at the Center for the Study and Treatment of Psychological Trauma (NET-TRAUMA), of Hospital de Clínicas de Porto Alegre (HCPA), Brazil. NET-TRAUMA is a program designed for the care of victims of psychological trauma, and takes referrals from primary, secondary and tertiary care services in Porto Alegre. It is a 6-month rotation in the training of second year residents in Psychiatry of the HCPA. Initially, a screening visit is done by the third year Psychiatry resident, after which the patients are referred to the therapist responsible for their treatment, which consists of 6 , once weekly visits, on average. Treatment consists of a short psychodynamic formulation of the traumatic situation and additional cognitive-behavioral therapy and pharmacological management, as required. In addition, family evaluation and counseling are undertaken as appropriate.

After patients' first visit, the therapist was asked to complete the Assessment of Countertransference Scale (EACT) ${ }^{20}$ At the same day, the patient was asked to complete the following assessments: the Davidson Trauma Scale (DTS), ${ }^{21}$ the Standardized Assessment of Personality - Abbreviated Scale (SAPAS), ${ }^{22}$ the Beck's Depression Inventory (BDI), ${ }^{23}$ and the Portuguese version of the Defense Style Questionnaire (DSQ-40). ${ }^{24}$ The Clinical Global Impressions Scale (CGI ${ }^{25}$ was rated by an independent psychiatrist, at the screening visit.

The study took place over a 2-year period, between August 2005 and September 2007.

\section{Participants}

All the women who were victims of sexual violence, both during childhood and adulthood, seen at NET-TRAUMA between August 2005 and September 2007, were included in the sample, which constituted 40 female patients. The only exclusion criterion 
was the need for psychiatric hospitalization due to risk of suicide or psychosis.

Twenty-six therapists saw the 40 patients. The therapists were second year Psychiatry residents at HCPA; 11 were male and 15 were female. Their mean age was 27 years $(S D=3.4)$. Among the 40 visits that were performed, 26 were undertaken by female therapists $(65 \%)$ and 14 by male therapists (35\%). Eighty percent of the therapists had previous experience of treating, at least, one victim of sexual violence.

\section{Instruments}

Therapists' countertransference was investigated using the EACT. ${ }^{20}$ This scale lists 23 frequent countertransference feelings, which are divided into 3 clusters: feelings of closeness (10 items), feelings of distance (10 items) and feelings of indifference (3 items). The therapist rates the intensity of each feeling on a likert scale of 0 (not felt) to 3 (felt a lot) at the start, midpoint and at the end of the interview, yielding a mean score for each time-point and an overall score (the mean of the three time-point scores) for each cluster of feelings. This is a scale that can be filled in quickly, feasible in a clinical and teaching environment.

The presence of PTSD and depressive symptoms was measured by means of the $\mathrm{DTS}^{21}$ and by the BDI, ${ }^{23}$ respectively. These are self-rated measures frequently used in clinical and research settings. The Portuguese version of the $\mathrm{BDI}$ is validated ${ }^{26}$ and an adaptation of the DTS was made to our culture. ${ }^{27}$

The Standardized Assessment of Personality - Abbreviated Scale $\left(\right.$ SAPAS) ${ }^{22}$ consists of a structured and short interview for personality disorders, to be used in routine clinical care. SAPAS scores of 3 or higher at screening correctly identify the presence of a personality disorder (DSM-IV criteria) in 90\% of the participants. It can be used to identify individuals with high risk of having personality disorders in general adult psychiatric environment. This instrument was translated and adapted into Brazilian Portuguese, and was approved and authorized to be used by its author.

In order to assess the defense mechanisms, the Brazilian Portuguese Version of the DSQ-40 was used. The DSQ was devised by Bond et al. as a self-answering questionnaire with 67 items for assessing the conscious derivatives of the defense mechanisms. ${ }^{28}$ This scale attempts to identify how people deal with conscious or unconscious conflicts. The instrument may display scores for 20 single defenses and for 3 factors (mature, immature and neurotic). The single defense mechanism scores are calculated from the mean of the items of each defense mechanism and the score factors are calculated by the mean scores of the defenses, which are part of each factor. Each item is assessed on a 1 to 9 scale in which 1 indicates "totally disagree" and 9, "totally agree". The Portuguese version of the instrument was validated by Blaya et al. ${ }^{24}$

The $\mathrm{CGI}^{25}$ severity index assesses the clinician's impression on the extent of the patient's mental illness at that time. The scores range from 1 (normal; not mentally ill) to 7 (extremely severe disease). Although this instrument is well known, there are few studies about its psychometric characteristics. ${ }^{29}$

\section{Statistical methods}

Sample size calculation was based in the projection that at least 40 patients would be necessary in order to obtain a correlation coefficient equal or greater than 0.4 , at $80 \%$ power and 0.05 significance level. With this sample size, a multiple linear regression analysis with up to 4 independent variables could be performed.

The overall scores of the three groups of countertransference feelings according to the EACT, weighted for the number of items in each group, were compared using Friedman test. To evaluate whether the mean scores of the three interview times (within each cluster of feelings) differed, ANOVA for repeated measures, followed by the Bonferroni test, was used.

One-way ANOVA was performed to compare the overall score of each cluster of feelings between patients who suffered childhood (up to 12 years of age), adulthood past (more than 18 years of age and more than 3 months prior to the visit), and adulthood current (more than 18 years of age and less than 3 months prior to the visit) sexual violence, followed by the Tukey test. Furthermore, Student t-Test was used to compare overall score of each cluster of feelings between dichotomous variables. Pearson's Correlation was used to examine the association between continuous variables and EACT overall scores.

Multiple linear regression analysis were carried out and included all variables associated to the outcome (feelings of closeness, distance or indifference) in the bivariate analysis at a $\mathrm{p}<0.20$, with the aim of obtaining greater reliability in the results. All set of analysis was conducted for the overall sample and, subsequently, in the sample stratified by the gender of the therapist.

Considering that a therapist with deviant countertransference feelings could bias the results, we conducted a sensitivity analysis, in which the group of consultations done by a therapist was excluded, one by one, and the global scores of countertransference feelings were assessed. We defined that a therapist would be permanently excluded from the analysis if the overall scores of countertransference feelings were discrepant from those of the total sample when he or she was removed.

\section{Ethical issues}

All participants signed an informed consent form. This study was approved by HCPA Research Ethics Committee (number 05-222).

\section{Results}

Sensitivity analysis did not identify consistent differences in the overall scores of countertransference feelings when each therapist was removed from analysis. The demographic characteristics of the patients are depicted in Table 1 .

There was a significant difference between the overall scores of the three groups of countertransference feelings, with a predominance of feelings of closeness $($ Mean $=5.42, S D=1.25$ ) in relation to the feelings of indifference (Mean $=1.82, \mathrm{SD}=1.22$ ) and distance $(\mathrm{Mean}=1.57, \mathrm{SD}=1.08)($ chi-square $=49.67$, $\mathrm{df}=2, \mathrm{p}<0.001)$. The mean scores of the therapist's feelings of 
Table 1 - Demographic characteristics of the patients $(n=40)$

\begin{tabular}{lc}
\hline \multicolumn{1}{c}{ Variables } & $\mathbf{n}(\%)$ \\
\hline Age (mean; standard deviation) & $34.7 ; 15.2$ \\
Ethnicity & \\
White & $32(80.0)$ \\
Mixed & $6(15.0)$ \\
Black & $2(5.0)$ \\
Schooling & \\
Elementary & $17(44.7)$ \\
High School & $17(44.7)$ \\
College/University & $4(10.5)$ \\
Marital status & \\
Single & $16(41.0)$ \\
Married & $18(46.2)$ \\
Divorced & $2(5.1)$ \\
Widowed & $3(7.7)$ \\
Activity & \\
Employed & $14(37.9)$ \\
Unemployed & $9(24.3)$ \\
Retired / On leave & $10(27.0)$ \\
Student & $4(10.8)$ \\
Time of trauma & \\
Up to 12 years of age & $12(30.0)$ \\
13 to 18 years of age & $1(2.5)$ \\
After 18 years of age, occurred more & $10(25.0)$ \\
than 3 months prior & \\
In the last 3 months & $17(42.5)$ \\
Episodes of sexual violence & \\
Repeated & $17(42.5)$ \\
Single & $23(57.5)$ \\
\hline & \\
\hline & \\
\hline &
\end{tabular}

closeness at the beginning of the visits (Mean $=16.08 \pm$ SD 5.81) were significantly different from the mean scores at the midpoint $($ Mean $=18.93 \pm S D 4.3)$ and at the end (Mean $=19.23 \pm S D$ 4.4) $(\mathrm{p}<0.001)$. Regarding the therapist's feelings of distance and those of indifference, there were no significant differences in the mean scores among the 3 visit times.

There was a significant association between therapists' feelings of closeness and the time when sexual violence occurred in the patient's life $(\mathrm{p}=0.043)$. The overall scores of the therapist's feelings of closeness were higher when interacting with patients who had been victimized in the preceding 3 months than for those who had been victimized after the age of 18 years, more than 3 months previously $(\mathrm{p}=0.037)$. There were no differences regarding the care of victims of sexual violence when it occurred before the age of 12 years (Table 2).

There was a significant association between patients CGI score and therapists' feelings of indifference $(r=0.35 ; \mathrm{p}=0.028)$. There was no association between the evaluated factors and the feelings of distance (Table 2).

Variables associated with the outcome at a $\mathrm{p}<0.20$ in bivariate analysis were included in multiple linear regression models, which were conducted separately for each cluster of feelings. On a multiple linear regression model, controlling for the patient's
SAPAS scores (association with the therapist's feelings of closeness at $p=0.159$ ), the significance of the association between the time of sexual violence and therapists' feelings of closeness was lost $\left(\mathrm{R}^{2}=\right.$ $0.020 ; p=0.090$ ). A multiple linear regression analysis performed with the therapist's feelings of indifference as an outcome included time of sexual violence $(\mathrm{p}=0.080)$, DSQ-40 mature factor $(\mathrm{p}=$ $0.054)$, DSQ-40 neurotic factor ( $\mathrm{p}=0.112)$, DSQ-40 immature factor $(\mathrm{p}=0.190)$, and CGI score $(\mathrm{p}=0.028)$. After such analysis, the association between the patient's CGI score and therapists' feelings of indifference lost statistical significance $\left(R^{2}=0.152\right.$; $\mathrm{p}=0.063)$.

There were no significant associations between therapists' countertransference feelings and any of the other factors in study (Table 2).

The sample was stratified according to therapists' gender. There were no significant associations between male therapists countertransference feelings and the factors in study.

Regarding the sample of patients seen by female therapists, a significant association between the DSQ- 40 mature factor scores of the patients and the therapists' feelings of indifference was observed $(r=-0.44 ; p=0.025)$. On this sample there was a significant association between patients' SAPAS scores and therapists' feelings of closeness $(r=-0.40 ; p=0.045)$ (Table 3).

In the multiple linear regression analysis controlled for the patient's CGI scores (association with therapists' feelings of indifference with $\mathrm{p}=0.111$ ), the significance of the association between DSQ-40 mature factor scores and the feelings of indifference was lost $\left(\mathrm{R}^{2}=0.218 ; \mathrm{p}=0.090\right)$. The association between patients' SAPAS scores and therapists' feelings of closeness held true after the multiple linear regression analysis controlled for the time of sexual violence (association with feelings of closeness with $\mathrm{p}=0.062$ ), resulting in $\mathrm{R}^{2}=0.151$ and $\mathrm{p}=0.038$.

\section{Discussion}

We documented a predominance of feelings of closeness in the care of the patients evaluated in this study. We did not detect a differential pattern of countertransference feelings associated with specific clinical characteristics. Therapists of both genders presented a similar pattern of empathic feelings towards women victims of sexual violence. In the subgroup of female therapists, we detected an inverse correlation between a higher probability of personality disorders in the patients and feelings of closeness in the therapists.

The therapists displayed more feelings of closeness toward patients, which increased from the midpoint to the end of the visits. One may suppose that the therapists, all at the beginning of their professional life, started the visit in a more defensive manner, afraid and insecure of the contact with patients and their traumatic histories. It is likely that, during the session, after the development of a relationship of empathy with the patients and greater involvement with their reports, the therapists might have been able to cope better with the initial impact of the contents, facilitating the appearance of feelings of closeness. 
Table 2 - Association between the mean scores of feelings of closeness, distance and indifference assessed by EACT and the factors in study

\begin{tabular}{|c|c|c|c|c|c|c|c|}
\hline \multirow[b]{2}{*}{ Factors in study } & \multicolumn{3}{|c|}{ Closeness } & \multicolumn{2}{|c|}{ Distance } & \multicolumn{2}{|c|}{ Indifference } \\
\hline & $\mathbf{N}$ & M (SD) & $\mathbf{p}$ & M (SD) & $\mathbf{p}$ & M (SD) & $\mathbf{p}$ \\
\hline Therapist's gender* & 40 & & 0.900 & & 0.686 & & 0.767 \\
\hline Male & 14 & $18.2(3.9)$ & & $4.9(4.1)$ & & $1.9(1.3)$ & \\
\hline Female & 26 & $18.0(4.4)$ & & $5.4(3.3)$ & & $1.8(1.2)$ & \\
\hline Time when sexual violence occurred ${ }^{\star \star}$ & 40 & & 0.043 & & 0.302 & & 0.080 \\
\hline Up to 12 years of age & & $17.6(4.4)$ & & $5.6(4.4)$ & & $2.5(1.5)$ & \\
\hline $\begin{array}{l}>18 \text { years of age, occurred more than } 3 \\
\text { months prior }\end{array}$ & & $15.7(4.4)$ & & $6.5(4.2)$ & & $1.5(1.0)$ & \\
\hline In the last 3 months & & $19.8(3.3)^{\dagger}$ & & $4.3(2.6)$ & & $1.6(1.0)$ & \\
\hline $\mathrm{CGI}^{\star \star \star \star}$ & 40 & $r=-0.16$ & 0.327 & $r=0.09$ & 0.557 & $r=0.35$ & 0.028 \\
\hline $\mathrm{BDI}^{\star \star \star \star}$ & 40 & $r=-0.08$ & 0.621 & $r=0.28$ & 0.074 & $r=0.07$ & 0.672 \\
\hline DTS $S^{* \star *}$ & 40 & $r=0.08$ & 0.639 & $r=0.10$ & 0.527 & $r=0.18$ & 0.260 \\
\hline DSQ - 40*** & 40 & & & & & & \\
\hline Mature factor & & $r=0.18$ & 0.269 & $r=0.09$ & 0.561 & $r=-0.30$ & 0.054 \\
\hline Neurotic factor & & $r=-0.03$ & 0.866 & $r=0.03$ & 0.858 & $r=-0.25$ & 0.112 \\
\hline Immature factor & & $r=0.08$ & 0.616 & $r=-0.07$ & 0.677 & $r=-0.21$ & 0.190 \\
\hline SAPAS $S^{\star \star \star}$ & 40 & $r=-0.23$ & 0.159 & $r=0.17$ & 0.293 & $r=0.03$ & 0.852 \\
\hline
\end{tabular}

EACT: Assessment of Countertransference Scale; CGI: Clinical Global Impressions Scale; BDI: Beck Depression Inventory; DTS: Davidson Trauma Scale; DSQ - 40: Defense Style Questionnaire; SAPAS: Standardized Assessment of Personality - Abbreviated Scale

* Student $t$-Test

**one-way ANOVA, followed by Tukey test

*** Pearson's coefficient correlation

${ }^{\dagger}$ Statistically significant difference at the level 0.05 relative to the group of patients whose trauma occurred after the age of 18 years, more than 3 months prior.

The gender of the therapists did not influence the pattern of countertransference feelings. This result is the opposite to that of Latts, who reported the predominance of feelings of distance in male therapists and of closeness in female therapists when facing situations of sexual violence. ${ }^{30}$ The hypothesis of Latts, that male therapists tend to become distant in response to the anxiety triggered by the contact with these patients, and that the women would be able to use empathy to shape this anxiety, ${ }^{30}$ was not confirmed in our sample. It is well known that there is a controversy among psychoanalytic authors about the relevance of the actual gender of patient and analyst in the course and prognosis of therapy. This study supports the view that the key factor is not the actual gender, but the role and the relationship that is established between patient and therapist. In this sense, we could infer that unconscious factors, among them fantasies, expectations of the patient, and the attitude and the way the therapist answer to them might be a more important point to be considered than the actual gender of both. After all, in psychoanalytic therapy we are mainly dealing with the internal reality, and the current study illustrates that this is the most relevant factor in this form of therapy. ${ }^{7}, 31$

There were no significant associations among the countertransference feelings and the depressive and PTSD symptoms, scores at personality disorders screening, and defensive style of patients. Such findings do not replicate the results of some other studies, such as those obtained by Mclntyre and Brody, revealing the influence of patients' diagnoses in the emotional reactions of therapists. ${ }^{8} 9$ However, our findings are consistent with those from Holmqvist, showing no relationship between the patients' diagnostic characteristics and the countertransference feelings triggered. ${ }^{32}$ It is important to emphasize that there are methodological differences between these studies and ours. First, the studies by Mclntyre, Brody, and Holmqvist included patients with different diagnosis or symptoms, and used different methods to evaluate them. ${ }^{8,9,32}$ Second, Brody used clinical vignettes and not in person interviews. ${ }^{9}$ Third, Brody and Mclntyre included therapists with diverse periods of experience, analyzing this variable as a predictor of countertransference. ${ }^{8,9}$ As previously described, we aimed to hold constant variables that might be potential confounders and included a relatively homogeneous group of patients (only women, victims of sexual abuse, referred to a single center) and therapists (same period of professional experience, only one interview with the patient). Methodological differences between studies are relevant for interpreting the divergent results.

In the sample stratified by patients seen by women therapists, inverse associations were observed between the patients' DSQ mature factor and the SAPAS scores and therapists' feelings of indifference and closeness, respectively. There is a likely connection between these findings, because the defensive style used by patients may be related to greater or smaller likelihood of personality disorders, reflected in the countertransference. After performing the multiple linear regression analyses, only the association between the SAPAS scores and the countertransference feelings of closeness remained significant. The inverse relationship between 
Table 3 - Association between the mean scores of feelings of closeness, distance and indifference assessed by EACT and the factors in study in the patients seen by female therapists $(n=26)$

\begin{tabular}{|c|c|c|c|c|c|c|}
\hline \multirow[b]{2}{*}{ Factors in study } & \multicolumn{2}{|c|}{ Closeness } & \multicolumn{2}{|c|}{ Distance } & \multicolumn{2}{|c|}{ Indifference } \\
\hline & M (SD) & $\mathbf{p}$ & M (SD) & $\mathbf{p}$ & M (SD) & $\mathbf{p}$ \\
\hline \multicolumn{7}{|l|}{ Time when sexual violence occurred ${ }^{*}$} \\
\hline Up to 12 years of age & $18.3(3.6)$ & 0.062 & $4.6(2.3)$ & 0.479 & $2.3(1.6)$ & 0.382 \\
\hline $\begin{array}{l}>18 \text { years of age, occurred more than } 3 \\
\text { months prior }\end{array}$ & $15.7(4.5)$ & & $6.5(4.2)$ & & $1.5(1.0)$ & \\
\hline In the last 3 months & $20.5(4.0)$ & & $4.9(2.6)$ & & $1.7(1.0)$ & \\
\hline $\mathrm{CGI}^{\star \star}$ & $r=-0.18$ & 0.384 & $r=0.30$ & 0.142 & $r=0.33$ & 0.111 \\
\hline $\mathrm{BDI}^{* *}$ & $r=-0.25$ & 0.217 & $r=0.37$ & 0.063 & $r=0.08$ & 0.705 \\
\hline DTS $^{\star \star}$ & $r=-0.10$ & 0.621 & $r=0.22$ & 0.272 & $r=0.19$ & 0.340 \\
\hline \multicolumn{7}{|l|}{ DSQ - 40** } \\
\hline Mature factor & $r=0.22$ & 0.264 & $r=0.06$ & 0.774 & $r=-0.44$ & 0.025 \\
\hline Neurotic factor & $r=-0.10$ & 0.611 & $r=0.12$ & 0.574 & $r=-0.16$ & 0.440 \\
\hline Immature factor & $r=-0.08$ & 0.706 & $r=0.03$ & 0.896 & $r=-0.18$ & 0.381 \\
\hline SAPAS ${ }^{\star \star}$ & $r=-0.40$ & 0.045 & $r=0.29$ & 0.155 & $r=0.07$ & 0.716 \\
\hline
\end{tabular}

EACT: Assessment of Countertransference Scale; CGI: Clinical Global Impressions Scale; BDI: Beck Depression Inventory; DTS: Davidson Trauma Scale; DSQ - 40: Defense Style Questionnaire; SAPAS: Standardized Assessment of Personality - Abbreviated Scale

* one-way ANOVA, followed by Tukey test

${ }^{\star \star}$ Pearson's correlation coefficient

these two variables is consistent with studies that relate the care of patients with specific personality disorders to characteristic countertransference feelings. ${ }^{8-11,33}$ There were no significant associations in the sample stratified of patients seen by male therapists, probably due to the small sample size.

The results of this study must be understood with their limitations. First, the patients assessed were seen by training psychiatrists in a specific program of care for victims of psychological trauma, in a tertiary hospital, which limits generalizing the findings. Second, there are limited data about the instrument that evaluated the outcome, the EACT. This is the first study that used EACT in a sample of victims of sexual violence, and the evaluation of its psychometric properties is necessary. However, we have previously evaluated the same sample with a different approach, the Content Analysis, and we detected results in the same direction, ${ }^{34}$ which corroborate our findings. Third, the therapists participating in this study were beginning their professional lives, with mean age of 27 years. This could make the assessment of countertransference feelings more difficult, because of their little experience in identifying them. Possibly, if the sample was formed by more experienced therapists, with an increased capacity of self-knowledge, different findings would be observed. Fourth, the fact that the patients face a time of extreme emotional shock may have influenced the way they completed the instruments, altering the measures of psychological disorders and defensive styles. However, it must be taken into account that all the patients were victims of sexual violence, and the entire sample was biased by this common denominator.

Although SAPAS is not a diagnostic scale, it screens with high predictive values and, because it is quick and easy to apply, it is quite appropriate to be used in clinical and teaching settings. This is especially true in a situation of extreme psychological distress, such as sexual violence. In the present study, the SAPAS absolute scores were utilized, and not its cutoff point because only one patient displayed a score lower than 3 .

It must be emphasized that the countertransference feelings assessed in this study were related to the first meeting of each dyad (patient-therapist), with the goal of analyzing therapists' acute countertransference reactions. Therefore, possible changes of the transference-countertransference relationship, which are common over the treatment, were not measured.

To understand better countertransference feelings triggered by the care of sexual violence victims may significantly benefit their treatment and prognosis, as well as the professional development of the therapists. We, thus, suggest that studies on such theme continue to be developed, using samples with different clinical characteristics, treated in different contexts.

\section{Conclusion}

Two conclusions may be inferred from this study: (1) female patients, victims of sexual violence, could express, irrespective of any other factor, mainly greater need of help and of protection, capable of evoking empathic responses of closeness in the therapists; and (2) the relative inexperience of the therapists, or their little time as professionals, did not affect their empathic capacities - at least within the learning and supervision context of a teaching hospital.

Lastly, it is important to stress that, due to the complexity of the issue and to its clinical relevance, further studies are necessary and appropriate to enhance its understanding.

\section{Acknowledgements}

The authors wish to thank Dr. Paul Moran for his helpful suggestions on this manuscript. 


\section{Disclosures}

\begin{tabular}{|c|c|c|c|c|c|c|c|}
\hline $\begin{array}{l}\text { Writing group } \\
\text { member }\end{array}$ & Employment & $\begin{array}{l}\text { Research } \\
\text { grant }^{1}\end{array}$ & $\begin{array}{l}\text { Other research grant or } \\
\text { medical continuous } \\
\text { education }\end{array}$ & $\begin{array}{l}\text { Speaker's } \\
\text { honoraria }\end{array}$ & $\begin{array}{c}\text { Ownership } \\
\text { interest }\end{array}$ & $\begin{array}{l}\text { Consultant/ } \\
\text { Advisory } \\
\text { board }\end{array}$ & Other ${ }^{3}$ \\
\hline Mariana Eizirik & Clinica privada & - & - & - & - & - & - \\
\hline $\begin{array}{l}\text { Sidnei } \\
\text { Schestatsky }\end{array}$ & $\begin{array}{c}\text { Clínica privada } \\
\text { UFRGS }\end{array}$ & - & - & - & - & - & - \\
\hline Leticia Kruel & Clínica privada & - & - & - & - & - & - \\
\hline $\begin{array}{l}\text { Lúcia Helena } \\
\text { Freitas Ceitlin }\end{array}$ & $\begin{array}{c}\text { Clinica privada } \\
\text { UFRGS }\end{array}$ & - & - & - & - & - & - \\
\hline
\end{tabular}

${ }^{*}$ Modest

** Significant

*** Significant: Amounts given to the author's institution or to a colleague for research in which the author has participation, not directly to the author. Note: UFRGS = Universidade Federal do Rio Grande do Sul.

For more information, see Instructions for Authors.

References

1. Freud S. The future prospects of psychoanalytic therapy (1910). In: Standard edition of the complete psychological works of Sigmund Freud. Rio de Janeiro: Imago; 1970. p.126-36.

2. Heimann P. On countertransference. Int J Psychoanal 1950;31:81-4.

3. Racker E. The meanings and use of countertransference. Psychoanal Q. 1957;26:303-57.

4. Winnicott D. Hate in countertransference. Int J Psychoanal. 1949;30:69-75.

5. Gabbard GO. Countertransference: the emerging common ground. Int $J$ Psychoanal. 1995;76(3):475-85.

6. Viederman M. The real person of the analyst and his role in the process of psychoanalytic cure. J Am Psychoanal Assoc. 1991;39(2):451-89.

7. Kernberg $\mathrm{O}$. The influence of the gender of patient and analyst in the psychoanalytic relationship. J Am Psychoanal Assoc. 2000;48(3):859-83.

8. Mclntyre SM, Schwartz RC. Therapists' differential countertransference reactions toward clients with major depression or borderline personality disorder. J Clin Psychol. 1998;54(7):923-31.

9. Brody EM, Farbier BA. The effects of therapist experience and patient diagnosis on countertransference. Psychotherapy. 1996;33(3):372-80.

10. Rossberg JI, Karterud S, Pedersen G, Friis S. An empirical study of countertransference reactions toward patients with personality disorders. Compr Psychiatry. 2007;48(3):225-30.

11. Betan E, Heim AK, Zittel Conklin C, Westen D. Countertransference phenomena and personality pathology in clinical practice: an empirical investigation. Am J Psychiatry. 2005;162(5):890-8.

12. Eizirik M, Schestatsky S, Knijnik L, Terra L, Ceitlin LHF. Countertransference and psychic trauma. Rev Psiquiatr RS. 2006;28(3):241-2.

13. Dalenberg CJ. Countertransference and the treatment of trauma. Washington, DC: American Psychological Association; 2000.

14. Pearlman LA, Saakvitne KW. The therapeutic relationship as the context for countertransference and vicarious traumatization. In: Trauma and the therapist. New York: W.W. Norton \& Company; 1995. p.15-34.

15. Leserman J. Sexual abuse history: prevalence, health effects, mediators, and psychological treatment. Psychosom Med. 2005;67(6):906-15.

16. Katerndahl D, Burge S, Kellogg N. Predictors of development of adult psychopathology in female victims of childhood sexual abuse. J Nerv Ment Dis. 2005;193(4):258-64.

17. Kendler KS, Bulik CM, Silberg J, Hettema JM, Myers J, Prescott CA. Childhood sexual abuse and adult psychiatric and substance use disorders in women: an epidemiological and cotwin control analysis. Arch Gen Psychiatry. 2000;57(10):953-9.

18. Romans SE, Martin JL, Morris E, Herbison GP. Psychological defense styles in women who report childhood sexual abuse: a controlled community study. Am J Psychiatry. 1999;156(7):1080-5.

19. Callahan KL, Hilsenroth MJ. Childhood sexual abuse and adult defensive functioning. J Nerv Ment Dis. 2005;193(7):473-9.

20. Eizirik CL. Rede social, estado mental e contratransferência: estudo de uma amostra de velhos da regiāo urbana de Porto Alegre [tese]. Porto Alegre: Universidade Federal do Rio Grande do Sul; 1997.
21. Davidson JR, Malik M, Travers J. Structural interwiew for PTSD. Psychometrical validation for DSM-IV criteria. Depress Anxiety. 1997;5(3):127-9

22. Moran P, Leese M, Lee T, Walters P, Thornicroft G, Mann A. Standardized Assessment of Personality - Abbreviated Scale (SAPAS): preliminary validation of a brief screen for personality disorder. Br J Psychiatry. 2003; 183:228-32.

23. Beck AT, Ward CH, Mendelson M, Mock J, Erbaugh J. An inventory for mesuring depression. Arch Gen Psychiatry. 1961;4:561-71.

24. Blaya C, Dornelles M, Blaya R, Heldt E, Kipper L, Bond M, Manfro GG. Brazilian-Portuguese Version of the Defense Style Questionaire (DSQ40) for the assessment of defense mechanisms: construct validity study. Psychother Res. 2007;17:261-72.

25. Guy W. ECDEU assessment manual for psychopharmacology - revised. Rockville, MD, US: Department of health, education, and welfare, public health service, alchohol, drug abuse, and mental health administration, NIMH Psychopharmacology research branch, division of extramural research programs; 1976.

26. Gorestein C, Andrade L. Inventário de depressão de Beck: propriedades psicométricas da versão em português. Rev Psiq Clin. 1998;25(5):245-50.

27. Hauck S, Schestatsky S, Terra L, Kruel L, Ceitlin LHF. Parental Bonding and emotional response to trauma: a study of rape victims. Psychother Res. 2007;17(1):83-90.

28. Bond M, Perry C, Gautier M, Goldenberg M, Oppenheimer J, Simand J. Validating the self-report of defense styles. J Personal Disord. 1989;3(2): $1-12$

29. Guy W. Clinical Global Impressions (CGI) Scale. In: Handbook of Psychiatric Measures. Washington, DC: American Psychiatric Association; 2000. p.100-2.

30. Latts MG, Gelso CJ. Countertransference behavior and management with survivors of sexual assault. Psychotherapy. 1995;32(3):405-15.

31. Eizirik CL. Masculinity, femininity and analytic relationship: countertransferential issues. In: Alcorta Garza A, editor. Psychoanalysis in Latin America. Monterrey: Fepal; 1995.

32. Holmqvist R, Armelius BA. The patient's contribution to the therapist's countertransference feelings. J Nerv Ment Dis. 1996;184(11):660-6.

33. Cornfield RB, Share IA. Countertransference in the treatment of the borderline personality. Psychiatr Clin North Am. 1994;17(4):851-61.

34. Eizirik M, Polanczyk G, Schestatsky S, Jaeger MA, Ceitlin LHF. Countertransference in the initial care of victims of sexual and urban violence: a qualitative-quantitative research. Rev Psiquiatr RS. 2007;29(2):197-204 